\title{
Solid-Phase Immunoassay of Polystyrene-Encapsulated Semiconductor Coreshells for Cardiac Marker Detection
}

\author{
Sanghee Kim, ${ }^{1}$ Jaetae Seo, ${ }^{2}$ Roopchan Ramdon, ${ }^{2}$ Hyeon-Bong Pyo, ${ }^{3}$ \\ Kyuho Song, ${ }^{4}$ and Byoung Hun Kang ${ }^{5}$ \\ ${ }^{1}$ Department of Biomedical Engineering, College of Health Science, Korea University, San 1, Jeongneung-3-dong, Seongbuk-gu, \\ Seoul 136-703, Republic of Korea \\ ${ }^{2}$ Department of Physics, Advanced Center for Laser Science and Spectroscopy, Hampton University, Hampton, VA 23668, USA \\ ${ }^{3}$ BioMed Team, Electronics and Telecommunications Research Institute, 131 Gajeong-Dong, Daejeon 305-700, Republic of Korea \\ ${ }^{4}$ Devices \& Materials Lab. LG Electronics, 16 Woomyeon-dong, Secho-gu, Seoul 137-724, Republic of Korea \\ ${ }^{5}$ Department of Mechanical Design Engineering, Korea Polytechnic University, 2121 Jungwang-Dong, Kyonggi-Do, \\ Siheung-City 429-793, Republic of Korea
}

Correspondence should be addressed to Jaetae Seo, jaetae.seo@hamptonu.edu

Received 7 October 2011; Accepted 3 January 2012

Academic Editor: Anukorn Phuruangrat

Copyright () 2012 Sanghee Kim et al. This is an open access article distributed under the Creative Commons Attribution License, which permits unrestricted use, distribution, and reproduction in any medium, provided the original work is properly cited.

A solid-phase immunoassay of polystyrene-encapsulated semiconductor nanoparticles was demonstrated for cardiac troponin I (cTnI) detection. CdSe/ZnS coreshells were encapsulated with a carboxyl-functionalized polystyrene nanoparticle to capture the target antibody through a covalent bonding and to eliminate the photoblinking and toxicity of semiconductor luminescent immunosensor. The polystyrene-encapsulated CdSe/ZnS fluorophores on surface-modified glass chip identified cTnI antigens at the level of $\sim \mathrm{ng} / \mathrm{mL}$. It was an initial demonstration of diagnostic chip for monitoring a cardiovascular disease.

\section{Introduction}

Polymer-encapsulated luminescent fluorophores are of great interest for the sandwich-type solid-phase immunoassay for monitoring selective biomolecular events of antigenantibody bindings on the polymer particle surface for lifescience applications of cardiac disease and cancer markers [1-3]. Conventional fluorophores of rodamines or fluorescein derivatives have been widely utilized for the solid-phase luminescent immunoassays [3-5]. However, these conventional fluorophores exhibited photobleaching and photoblinking, which limited their use in life-science applications [6].

Recently, CdSe/ZnS coreshells have been considered as the best fluorophores in biomedical and clinical applications, even though the potential cytotoxicity had been controversial. It is well known that semiconductor coreshells have high-quantum yields, size-dependent wide optical tunability, and high color purity [7-9]. CdSe semiconductor quantum dots (QDs) have a good photostability compared to conventional fluorophore dyes of rodamine or fluorescein derivatives without serious photobleaching problems for the biomedical applications $[10,11]$. CdSe/ZnS semiconductor coreshells significantly enhance quantum yield and reduce photoblinking $[12,13]$. With adequate polymer encapsulation, semiconductor coreshells eliminate photoblinking and toxicity. Hereafter, CdSe/ZnS is referred to as "QDs" instead of coreshells to avoid confusion with polystyreneencapsulated (shell) CdSe/ZnS (core).

A schematic drawing of sandwich-type solid-phase immunosensor is shown in Figure 1. The surface of polystyrene-encapsulated $\mathrm{CdSe} / \mathrm{ZnS}$ was carboxylated to capture antibody through covalent bonding $[14,15]$. The capture antibody targets the analytes for probing the biomolecules. The polystyrene surface was carboxylized with either onestep batch [16] or two-step emulsion polymerization in 


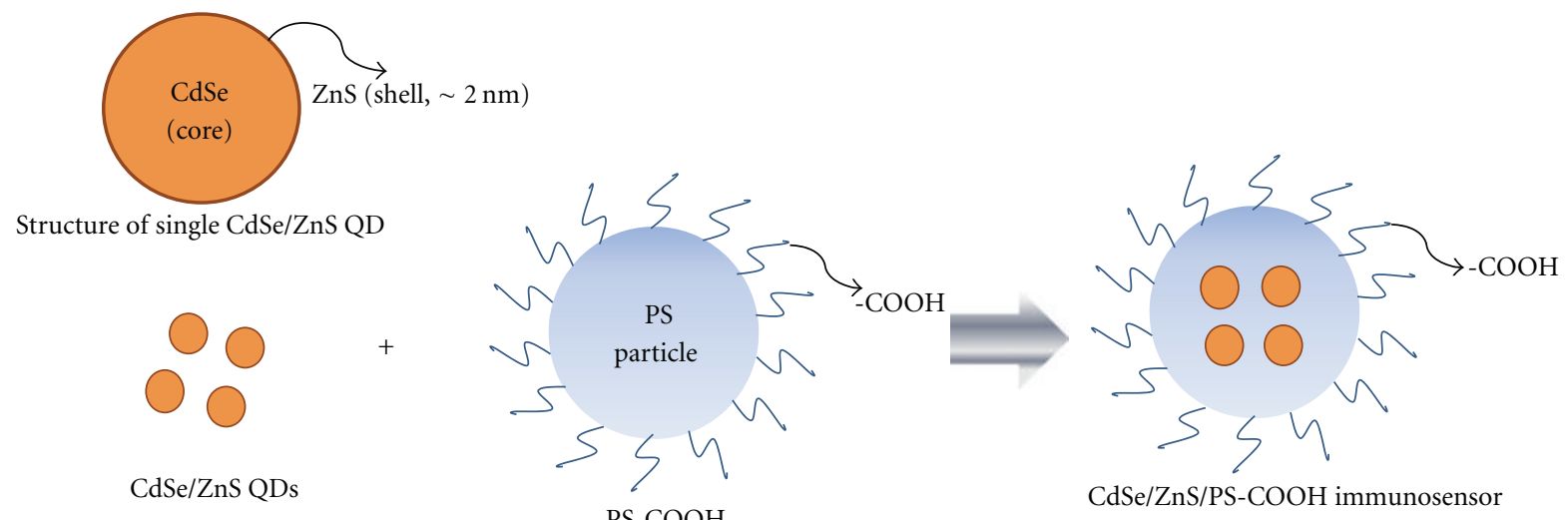

(a)

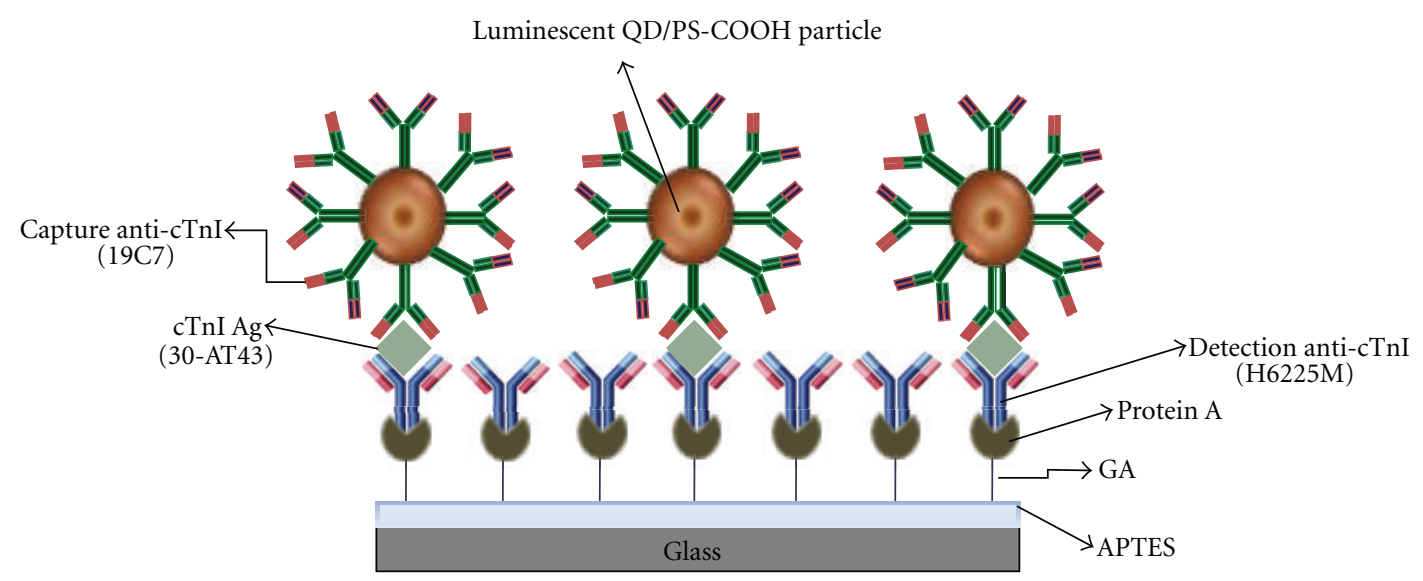

(b)

FIGURE 1: Schematic diagram of sandwich-type solid-phase immunoassay with CdSe/ZnS/PS-COOH fluorophores on surface-modified glass chip for cTnI antigen analysis.

the presence of functional comonomer of acrylic acid (AA) [17]. The chip surface was functionalized with 3aminopropyltriethoxysilane (APTES)/glutaraldehyde (GA) to form activelinker of aldehyde groups, which were coupled with amino groups of protein A [18]. Protein A provides high immunoassay sensitivity as an additional molecule linker, because it immobilizes the detection antibody on the chip surface with its biologically active Y-shaped orientation [19, 20].

This paper demonstrated a solid-phase immunoassay on a glass chip biosensor. The biosensor consisted of capture antibody, carboxylated-polystyrene-CdSe/ZnS coreshells, and detection antibody on the APTES/GA/Protein A. The antigen analyte was sandwiched between the antibodies. The glass chip biosensor could be utilized to detect cTnI for sensing cardiovascular disease with a fluorescence readout technique. The glass chip biosensor successfully recorded the linear increase of fluorescence intensity as the concentration of cTnI antigen was increased.

\section{Experiment}

For preparing the glass chip immunosensor, styrene, divinylbenzene (DVB), potassium peroxosulfate (KPS), 3Aminopropyltriethoxysilane (APTES), 25-wt $\%$ glutaraldehyde $\left(\mathrm{CHO}-\mathrm{CH}_{2} \mathrm{CH}_{2} \mathrm{CH}_{2}-\mathrm{CHO}\right.$ ), sodium cyanoborohydride $\left(\mathrm{NaBH}_{2} \mathrm{CN}\right)$, EDC (1-Ethyl-3-[3-dimethylaminopropyl] carbodiimide hydrochloride) and Sulfo-NHS were purchased from Sigma Aldrich (USA). The functional comonomer (AA) was purchased from Junsei Chemical (Japan). Cardiac troponin I (cTnI, cat \#30-AT43) as antigen and capture anti-cTnI (cat \#4T21-19C7, $1 \mathrm{mg} / \mathrm{mL}$ ) was purchased from Fitzgerald (USA) and Hytest (Finland), respectively. The detection anti-cTnI (cat \#H86625M, $6 \mathrm{mg} / \mathrm{mL}$ ) and recombinant Protein A (product \#21184) were purchased from Biodesign (USA) and Pierce (USA), respectively.

Carboxylated Polystyrene (PS-COOH) nanoparticles were synthesized with an emulsion polymerization technique. In the one-step batch polymerization method, styrene monomer, functional comonomer of $\mathrm{AA}$ and $\mathrm{DVB}$ were 


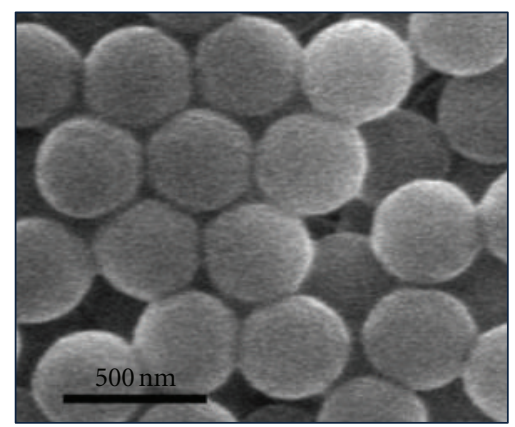

(a)

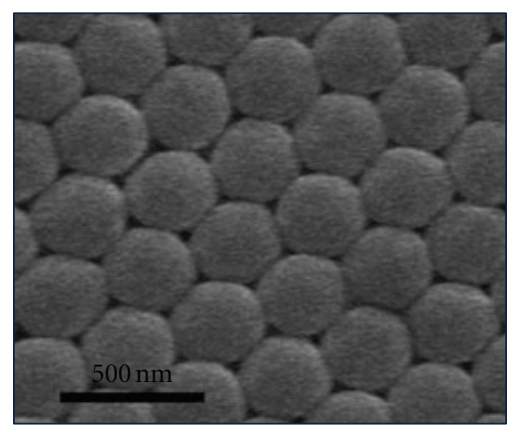

(c)

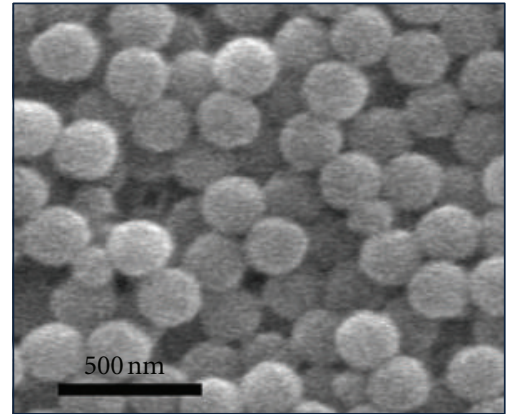

(b)

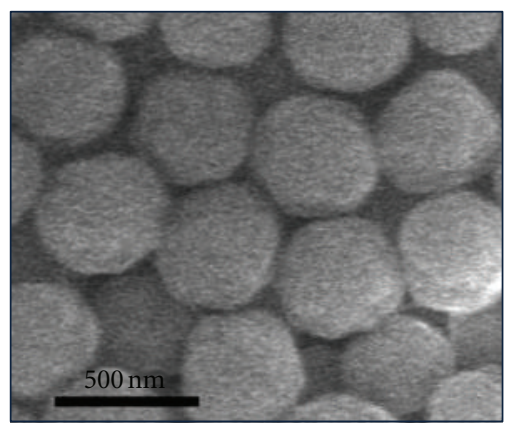

(d)

FIGURE 2: SEM images of carboxylated polystyrene nanoparticles: (a) PS-COOH \#1, (b) PS-COOH \#2 with one-step batch polymerization, (c) PS-COOH \#3, and (d) PS-COOH \#4 with two-step polymerization.

mixed into 200-mL deionized water in a 500-mL round bottom neck flask and were heated up to $\sim 70^{\circ} \mathrm{C}$ by swiftly adding KPS (0.05 g). The polymerization process was continued overnight under nitrogen purging. For two-step polymerization, the functional comonomer was added after 2 hours, at which point the primary polymerization was initiated. The morphology of PS-COOH was characterized with a field emission scanning electron microscope (FESEM, Sirion, FEI), after the colloidal particles were purified by removing a crude fraction of chemicals by centrifugation redispersion. The $D_{\mathrm{h}}$ and zeta $(\zeta)$ potential value of the purified PS nanoparticles was measured by dynamic light scattering (DLS) (ELS-700, Otsuka Electronics Co. Ltd.) using a $10-\mathrm{mW}$ He-Ne laser. The averaged valued of $\zeta$ potential was estimated after the PS nanoparticles were dispersed in DI water, and buffer solution of PBS 1\% TX100 and a sodium bicarbonate $\left(\mathrm{NaHCO}_{3}\right)$. The purified PS nanoparticles were dried for $\sim 15 \mathrm{~min}$ at $\sim 65^{\circ} \mathrm{C}$ for the X-ray photoelectron spectroscopy (ESCA LAB 210D (VG Scientific Ltd, UK)). A monochromatic Al K $\alpha$ X-ray source at $250 \mathrm{~W}$ $(12.5 \mathrm{KV})$ was used to scan a wide energy range from $\sim 0$ to $\sim 1.1 \mathrm{KeV}$. The spectra for $\mathrm{C} 1 \mathrm{~s}$ and $\mathrm{O} 1 \mathrm{~s}$ signals were recorded with $50-\mathrm{eV}$ pass energy, 0.05-eV energy step size, and 200-ms dwell time. An iterative fitting program (thermo advantage 3.31) was used to deconvolute the XPS peaks. The peakfitting was continued until the fitting was acceptable. The C1s electron binding energy, which corresponded to $\sim 284.6 \mathrm{eV}$ of graphitic carbon, was used as a reference position relative to the other peaks.
The absorption and fluorescence spectra of CdSe/ZnS QDs were characterized by a UV/Vis/NIR spectrophotometer (U-3501, HITACHI/USB4000, Ocean Optics). CdSe/ZnS QDs $(\sim 150 \mu \mathrm{L})$ were diffused into the swollen PS-COOH particles (PS-COOH \#3, $0.5 \mathrm{~mL}$ ) in $\sim 1.5-\mathrm{mL}$ chloroform $(5 \%, \mathrm{v} / \mathrm{v}) /$ pronanol $(95 \%, \mathrm{v} / \mathrm{v})$ for $\sim 30 \mathrm{~min}$ at $64^{\circ} \mathrm{C}$ as the schematic diagram was shown in Figure 1(a). The incorporation of QDs into the PS nanoparticles was completed when the QD/PS-COOH nanoparticles were cooled down in the ice water. Following the incorporation process, the particles were characterized using a TEM (JEM-2000 FxII, JEOL, Japan) with an acceleration voltage at $200 \mathrm{kV}$ and an $\mathrm{X}$ ray diffraction (XRD, RU-200BHD, Rigaku) with operation conditions of $40 \mathrm{kV}$ and $40 \mathrm{~mA}$ in the range of $2 \theta$ value between $10^{\circ}$ and $90^{\circ}$ in steps of $0.02^{\circ}$ with a speed of $3^{\circ} / \mathrm{min}$. For fabricating the luminescent immunosensor, a buffer was exchanged by incubating $10 \mu \mathrm{L}$ of QD/PS-COOH particles (PS-COOH \#3, $6.2 \times 10^{9}$ ) with $1 \mathrm{~mL}$ of a MES buffer (4Morpholineethanesulfonic acid, $100 \mathrm{mM}, \mathrm{pH}$ 6.0). After the mixture was centrifuged at $14,000 \mathrm{rpm}$ for $\sim 30 \mathrm{~min}$ at $\sim 4^{\circ} \mathrm{C}$ twice, the pellet fraction of QD/PS-COOH particles was incubated with $500 \mu \mathrm{L}$ of $0.1 \mathrm{M}$ EDC/NHS for $\sim 20 \mathrm{~min}$ at room temperature. The mixture was centrifuged again at $14,000 \mathrm{rpm}$ for $\sim 30 \mathrm{~min}$ at $\sim 4^{\circ} \mathrm{C}$. Then, the pellet was rinsed with DI water and incubated with $2 \mu \mathrm{L}$ of capture anti-cTnI (\#4T21-19C7, $2 \mu \mathrm{g}, 3.02 \times 10^{12}$ molecules) overnight. Finally, the PS-COOH-encapsulated $\mathrm{CdSe} / \mathrm{ZnS}$ QD fluorophores were collected as a pelletized mixture after the mixture was centrifuged again at $14.000 \mathrm{rpm}$ for $\sim 30 \mathrm{~min}$ at $\sim 4^{\circ} \mathrm{C}$. 


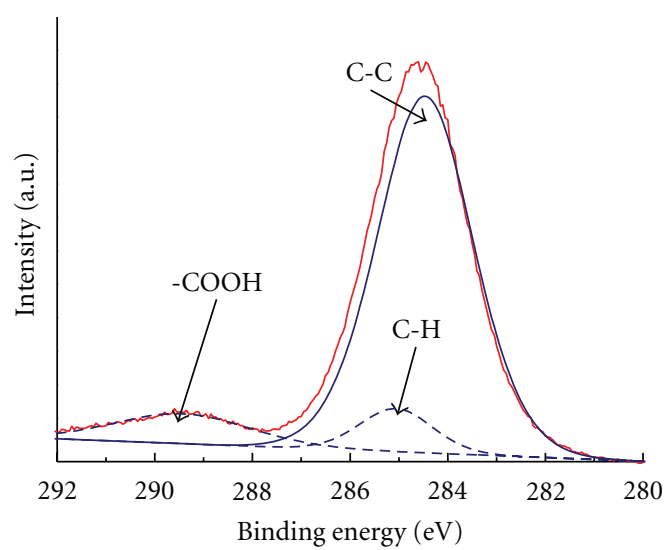

(a)

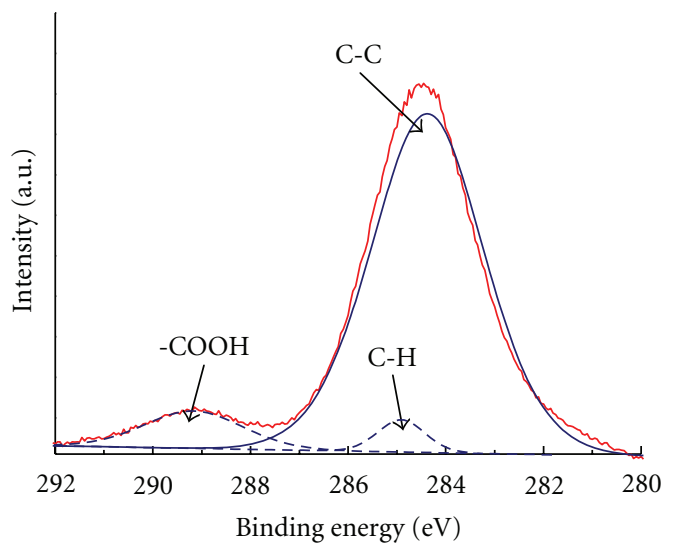

(c)

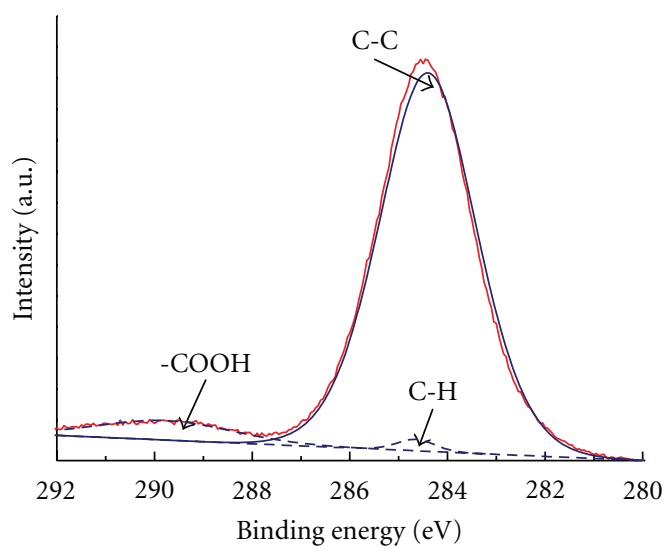

(b)

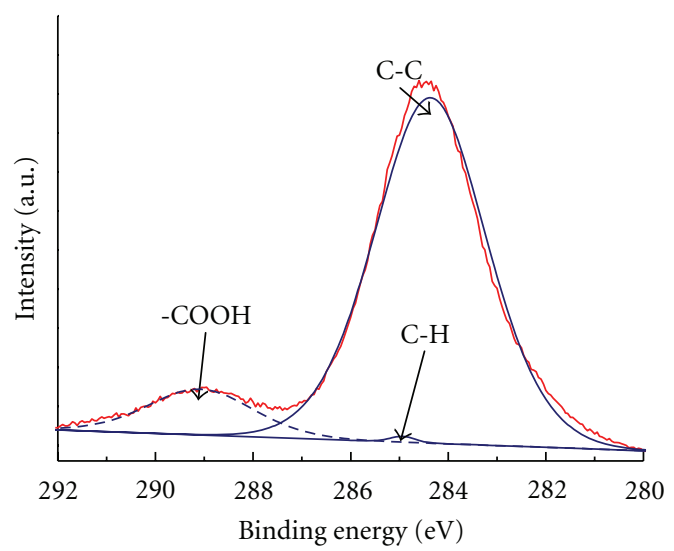

(d)

FIGURE 3: C1s core level scan: photoelectron peaks at characteristic binding energy regions: (a) PS-COOH \#1, (b) PS-COOH \#2 with the one-step batch polymerization, and (c) PS- $\mathrm{COOH} \# 3$ and (d) PS-COOH \#4 with the two-step polymerization.

The glass surface was functionalized with plasma etching for $\sim 60 \mathrm{sec}$ to add $-\mathrm{OH}$ groups and silanized in ethanol $(0.5 \%$, DI water) containing APTES ( $2 \mathrm{wt} \%)$. The aminosilanized surface was rinsed with ethanol, and baked at $\sim 120^{\circ} \mathrm{C}$ for $\sim 15 \mathrm{~min}$. It was then treated with $\sim 10$-mL GA solution $(25 \mathrm{wt} \%)$ with $0.1 \%$ sodium cyanoborohydride for $\sim 4 \mathrm{~h}$ at room temperature to induce $\mathrm{CHO}$ groups, and rinsed with DI water. The $\mathrm{NH}_{2}$ group on recombinant Protein A was coupled with the $\mathrm{CHO}$ group on the APTES/GA on the surface of glass chip. Each surface modification of glass chip was analyzed using an AFM (Park Systems, XE-100) with a silicon tip (Nanosensors, NCHR) in noncontact mode to obtain the topographic images and $R_{\mathrm{a}}$ value. The protein A $\left(5 \mu \mathrm{g} / \mathrm{mL}, 3.5 \times 10^{11}\right.$ molecules) with volume of $\sim 4.5 \mu \mathrm{L}$ was applied on the glass chip and incubated for $\sim 30 \mathrm{~min}$ at room temperature. Two different volumes of detection anti-cTnI, $4.5 \mu \mathrm{L}\left(27 \mu \mathrm{g}, 1.08 \times 10^{12}\right.$ molecules $)$ and $2.25 \mu \mathrm{L}(13.5 \mu \mathrm{g}$, $5.42 \times 10^{11}$ molecules) were introduced into each well, incubated for $\sim 15 \mathrm{~min}$ at room temperature, and rinsed with PBS. The primary antigen antibody reaction was facilitated by incubating cTnI antigen, $\sim 0.5 \mathrm{ng} / \mathrm{mL}\left(\sim 8.75 \times 10^{7}\right)$, $\sim 1.0 \mathrm{ng} / \mathrm{mL}\left(\sim 1.75 \times 10^{8}\right)$, and $\sim 2.0 \mathrm{ng} / \mathrm{mL}\left(\sim 3.5 \times 10^{8}\right)$, with detection anti-cTnI in each well for $\sim 15 \mathrm{~min}$ at room temperature. After each well was rinsed with PBS, the secondary antigen-antibody reaction was generated by adding $\sim 7-\mu \mathrm{L}$ CdSe/ZnS-PS fluorophores $\left(\sim 4.34 \times 10^{9}\right.$ particles $)$ in each well, where cTnI/detection anti-cTnI complex was already formed. The reaction was completed, after it was incubated for $\sim 15 \mathrm{~min}$ at room temperature and each well was rinsed with PBS.

\section{Results and Discussions}

The DLS measurement results, $D_{\mathrm{h}}$ and $\zeta$ potential values of the PS nanoparticles for the same amounts of monomer and comonomer using different polymerization methods, are listed in Table 1. SEM images of the spherical particles are shown in Figure 2. The morphology of particles was independent of the polymerization methods. The negatively charged AA acted as an ionic surfactant for surface functionalization, which stabilized the particle surface at the polymer/water interface. The zeta $(\zeta)$ potential value indicated the presence of $\mathrm{COOH}$ driven by the AA. The zeta $(\zeta)$ potential value and surface charge density of PS- $\mathrm{COOH}$ 
TABLE 1: DLS characterization of PS-COOH particles with two different fractions of comonomer (AA) with either one-step or two-step emulsion polymerization.

\begin{tabular}{lccccccc}
\hline \multirow{2}{*}{ PS-COOH } & \multirow{2}{*}{ AA fraction $(\%)$} & \multicolumn{3}{c}{$D_{\mathrm{h}}$ of PS-COOH particles $(\mathrm{nm})$} & \multirow{2}{*}{ ( potential $(\mathrm{mV})$} & \multirow{2}{*}{ Surface Charge density $\left(\mu \mathrm{C} / \mathrm{cm}^{2}\right)$} \\
\hline PS-COOH \#1 & 10 & 482.9 & 563.7 & 549.7 & 607.4 & -24.7 & -2.14 \\
PS-COOH \#2 & 20 & 340.4 & 436.2 & 362.5 & 377.3 & -22.6 & -1.95 \\
PS-COOH \#3* & 10 & 255.8 & 271.8 & 251.6 & 280.8 & -37.0 & -3.50 \\
PS-COOH \#4* & 20 & 540.1 & 716.3 & 579.4 & 776.5 & -28.9 & -2.61 \\
\hline
\end{tabular}

${ }^{*}$ Two-step emulsion polymerization.

TABLE 2: XPS analysis of PS-COOH nanoparticles.

\begin{tabular}{lcccc}
\hline PS- $\mathrm{COOH}$ & {$[\mathrm{C} 1 \mathrm{~s}]$ atomic $\%$} & {$[\mathrm{O} 1 \mathrm{~s}]$ atomic $\%$} & {$[\mathrm{O} 1 \mathrm{~s}] /[\mathrm{C} 1 \mathrm{~s}]$} & 0.20 \\
\hline PS-COOH \#1 & 83.5 & 16.4 & 0.14 & $\mathrm{C}_{\mathrm{COOH}} / \mathrm{C}_{\text {Total }}$ \\
PS-COOH \#2 & 87.8 & 11.9 & 0.28 & 0.117 \\
PS-COOH \#3* & 77.9 & 21.9 & 0.27 & 0.096 \\
PS-COOH \# $4^{*}$ & 78.4 & 21.5 & 0.125 \\
\hline
\end{tabular}

${ }^{*}$ Two-step emulsion polymerization.

particles with two-step polymerization were relatively higher than those created using the one-step method. The PS$\mathrm{COOH}$ particles prepared under two-step method with $\sim 10 \%$ AA fraction displayed the highest zeta potential values as shown in Table 1 . The $D_{\mathrm{h}}$ of the PS nanoparticles increased as the PH increased. The highest $D_{\mathrm{h}}$ value for the PS nanoparticles was in the dispersion medium of sodium bicarbonate $(\mathrm{pH} 8.3)$, because of the swollen hairy layer of carboxyl groups on the particle surface [21]. In the nonionic surfactant of TX-100, the $D_{\mathrm{h}}$ of PS-COOH \#1 and PS-COOH \#4 increased compared to that of PS- $\mathrm{COOH}$ particles in $\mathrm{DW}$, where as the values of PS- $\mathrm{COOH} \# 2$ and PS-COOH \#3 did not increase. The changes of $D_{\mathrm{h}}$ values indicate the hydrophilicity of particle surface, because the packing of nonionic surfactant was loosened as the hydrophilicity of particle surface was increased $[22,23]$. This result implies that PS-COOH \#3 is a good candidate for an immunosensor compared to the other types of particles; this is because the surface of PS- $\mathrm{COOH} \# 3$ became relatively stable with a larger number of functional carboxyl groups.

The degree of surface carboxylation of PS- $\mathrm{COOH}$ nanoparticles was characterized by the XPS analysis of $\mathrm{C} 1 \mathrm{~s}$ and O1s peaks [24]. The O1s peak in the XPS survey spectra was observed with all types of PS-COOH nanoparticles. The O1s peak from bare PS nanoparticles was not observed. It indicated the presence of $\mathrm{COOH}$ groups on the particle surface. No observation of $\mathrm{O} 1 \mathrm{~s}$ peak indicated that there was no carboxylation on the surface. The $\mathrm{C} 1$ s core-level scan spectra for all PS-COOH particles exhibited a newly emerged peak at $\sim 289.2 \mathrm{eV}$. It indicated the presence of $\mathrm{COOH}$ group, which was generated from AA. It was independent of particle preparation methods, beside the main C1s peak at $\sim 284.5 \mathrm{eV}$ as shown in Figure 3 [25]. The intensity of O1s peaks from PS-COOH nanoparticles with two-step preparation method was higher than the intensity from the nanoparticles with one-step batch condition. The O1s peak intensity from PS-COOH nanoparticles with two-step preparation was increased as $[\mathrm{O}]:[\mathrm{C}]$ ratio was increased as shown in Table 2. The larger content of AA with higher $[\mathrm{O}]:[\mathrm{C}]$ ratio provided better hydrophilicity on the particle surface. $[\mathrm{O}]:[\mathrm{C}]$ ratio of PS-COOH \#3 surface was slightly higher than that of PS-COOH \#4 with two-step polymerization. This indicated that PS-COOH \#3 had a better hydrophilic property than PS-COOH \#4 had. The particle surface with better hydrophilicity possessed abundant $\mathrm{COOH}$ group, which provided the higher $\zeta$ potential value. In two-step method, the higher AA content on the surface induced more $\mathrm{COOH}$ atomic $\%$ which could be characterized at $\sim 289.2 \mathrm{eV}$, while the hydrocarbon (C-C, C-H) component was decreased as shown in Figures 3(c) and 3(d) [26]. The increase of $[\mathrm{O}]:[\mathrm{C}]$ ratio suggested that the two-step method induced a higher efficiency on surface carboxylation at a given experimental condition. To determine the degree of surface carboxylation, the ratio of $\mathrm{C}_{\mathrm{COOH}} / \mathrm{C}_{\mathrm{Total}}$ was calculated based on the atomic \% of carbons at $\sim 289.2 \mathrm{eV}$ compared to the total amount of hydrocarbon component (C-C, C-H) at $\sim 284.2 \mathrm{eV}$ and $\sim 284.9 \mathrm{eV}$ [27]. The degree of surface carboxylation, $\mathrm{C}_{\mathrm{COOH}} / \mathrm{C}_{\mathrm{Total}}$ ratio, with two-step method was relatively higher than those of the one-step method as shown in Table 2. For example, the $\mathrm{C}_{\mathrm{COOH}} / \mathrm{C}_{\text {Total }}$ value of PS-COOH \#3 (10\% AA) was $\sim 0.096$, while that of the PS-COOH \#2 (20\% AA) was $\sim 0.070$. This showed that the polymerization method was directly linked to the control of surface carboxylation degree on PS particles. These results suggested that the two-step method provided better surface carboxylation on the PS nanoparticles than the one-step batch polymerization.

$\mathrm{CdSe} / \mathrm{ZnS} / \mathrm{PS}-\mathrm{COOH}$ particles were characterized with UV-Vis absorption, fluorescence, and TEM analyses. The absorption and fluorescence peaks of bare CdSe/ZnS QDs were exhibited $\sim 584 \mathrm{~nm}$ and $\sim 596 \mathrm{~nm}$, respectively, as shown in Figure 4(a) with black and red solid lines. The Stokes shift of bare CdSe/ZnS QDs in water was $\sim 12 \mathrm{~nm}$. The fluorescence emission peak of the CdSe/ZnS-PS-COOH displayed a slight red-shift $\sim 0.5 \mathrm{~nm}$ from that of bare CdSe/ZnS QDs as shown by the blue dash line in Figure 4(a). The 
fluorescence red shifts of CdSe/ZnS QDs in polysaccharide nanocomposites $(\sim 4 \mathrm{~nm})$ or polymer microspheres $(\sim 5 \mathrm{~nm})$ were also observed early [28, 29], which indicated welldispersed QDs or reduction of homoenergy transfer.

The typical TEM images of Figure 4(b) displayed unfilled-cavity PS nanoparticles (PS-COOH $\# 3, D_{\mathrm{h}} \approx$ $250 \mathrm{~nm}$ ), which was a similar image of hollow-like PS nanoparticle matrix $[14,30]$. The inset of Figure 4(b) was the typical TEM image of CdSe/ZnS QDs. The incorporation of $\mathrm{CdSe} / \mathrm{ZnS}$ QDs in the void space of PS-COOH nanoparticle (Figure 4(c)) presented contrast alternations within the spherical structure compared to the TEM image of Figure 4(b). It implied that CdSe/ZnS QDs in a liquid phase were diffused through the pores and were hydrophobically adsorbed on the interior of the PS-COOH particle. The incorporation of CdSe/ZnS QDs in PS-COOH was confirmed again using an X-ray diffraction (XRD) as shown in Figure 4(d). The XRD displayed the two phases of amorphous polystyrene and CdSe/ZnS peaks. The broad peak around $2 \theta=20^{\circ}$ was due to the presence of amorphous polystyrene $[31,32]$. The diffraction peaks around $25.6^{\circ}$, $43.4^{\circ}$, and $54.5^{\circ}$ corresponded to (111), (220), and (311) lattice planes of CdSe. The diffraction peaks of QD/PS$\mathrm{COOH}$ immunosensor were slightly shifted to a higher angle compared to the peak positions of CdSe at $25.3^{\circ}, 42.2^{\circ}$, and $50.0^{\circ}$ [33], because of the existence of $\mathrm{ZnS}$ shell on the CdSe $[34,35]$.

Both 3D surface morphology and $R_{\mathrm{a}}$ value of bare, APTES/GA, and APTES/GA/protein A layer on a glass chip surface were characterized by AFM measurement. The surface of bare glass chip exhibited a uniform topology with a $R_{\mathrm{a}}$ value of $\sim 0.2 \pm 0.09 \mathrm{~nm}$ as shown in Figure 5(a), while the surface of glass chip with APTES/GA-modification displayed a cloud-like wavy structure having a small protrusion as shown in Figure 5(b). The 3D surface morphology alternation indicated that the surface of bare glass chip was covered with chemically bound materials with APTES/GA layer formation. The increased $R_{\mathrm{a}}$ value of $\sim 1.69 \pm 0.07 \mathrm{~nm}$, compared to that of the bare glass chip surface $(0.2 \pm$ $0.09 \mathrm{~nm}$ ), was coincident with the $R_{\mathrm{a}}$ value of APTES/GA treatment [36]. The AFM image of protein A layer, displayed a newly emerged-cluster of globular structure with a height value of $\sim 3.16 \pm 0.13 \mathrm{~nm}$ as shown in the Figure 5(c). The height corresponded to the dimension of the protein A layer for monolayer formation [37]. The thickness increase of protein A layer suggested that the Protein A was strongly bound to the APTES/GA layer without aggregation and that the protein was not denaturalized because the mean size of Protein A in solution was known as $\sim 3 \mathrm{~nm}$ [38].

The AFM images of complete CdSe/ZnS/PS immunoassay are shown in Figure 5(d). The 3D AFM image of Figure 5(d) exhibited the spherical shape of CdSe/Zn-PS$\mathrm{COOH}$ with detection anti-cTnI, which was immobilized on protein A layer as shown in Figure 1(b). The glass chip surface without CdSe/ZnS-PS-COOH immunosensor displayed a cluster-like globular shape, which indicated the presence of detection anti-cTnI. The AFM image was also evidenced with early report [39]. According to AFM images, the height and width of CdSe/ZnS-PS-COOH immunosensor

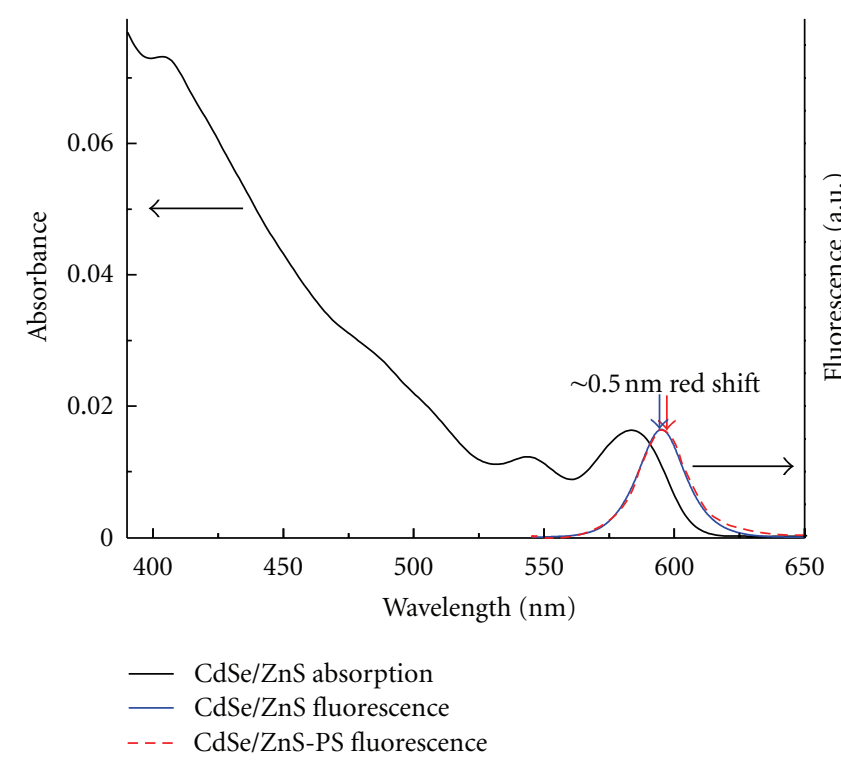

(a)

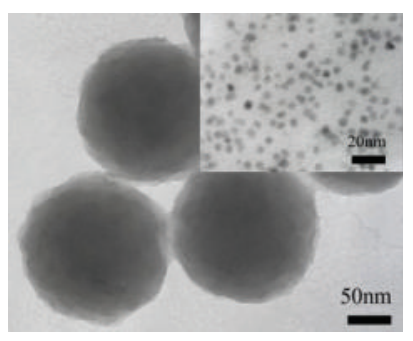

(b)

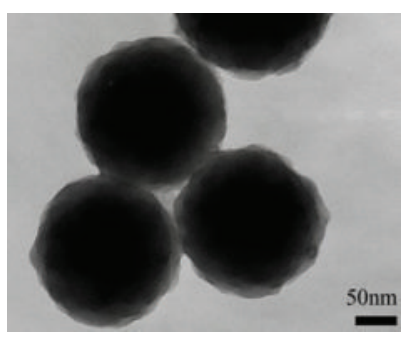

(c)

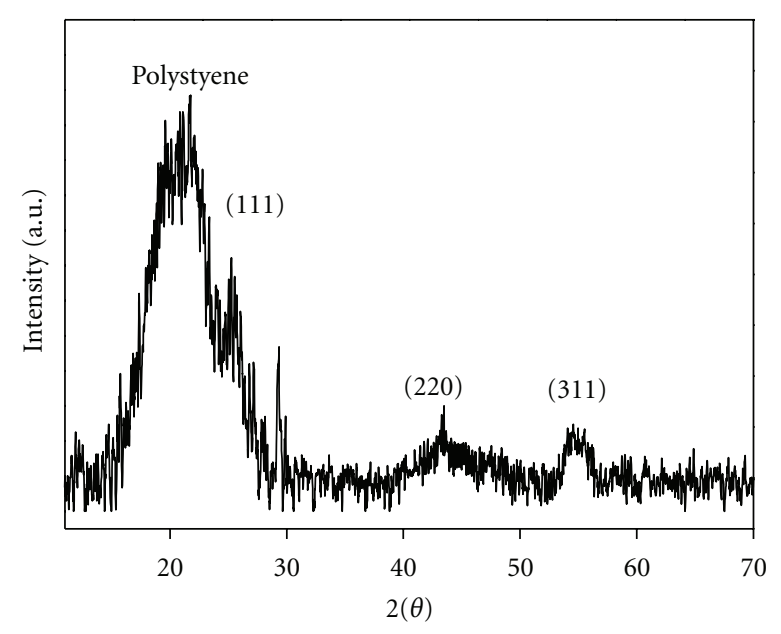

(d)

Figure 4: (a) UV-Vis absorption spectrum (black solid line) and normalized fluorescence spectra of CdSe/ZnS QDs (red solid line) and $\mathrm{CdSe} / \mathrm{ZnS} / \mathrm{PS}-\mathrm{COOH}$ particles (blue dash line), (b) typical TEM image of PS-COOH particles cavity without CdSe/ZnS, and $\mathrm{CdSe} / \mathrm{ZnS}$ coreshells (inset), (c) typical TEM image of CdSe/ZnSPS-COOH particles, and (d) X-ray diffraction pattern of CdSe/ZnSPS-COOH particles. 


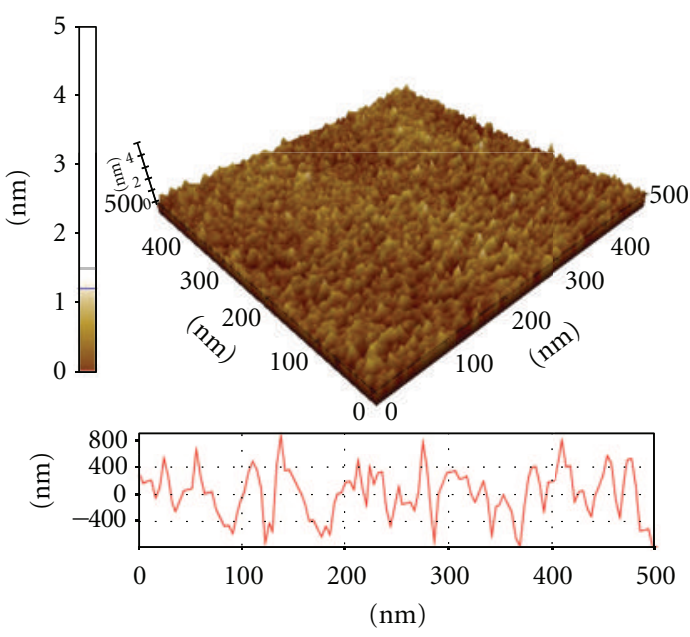

(a)

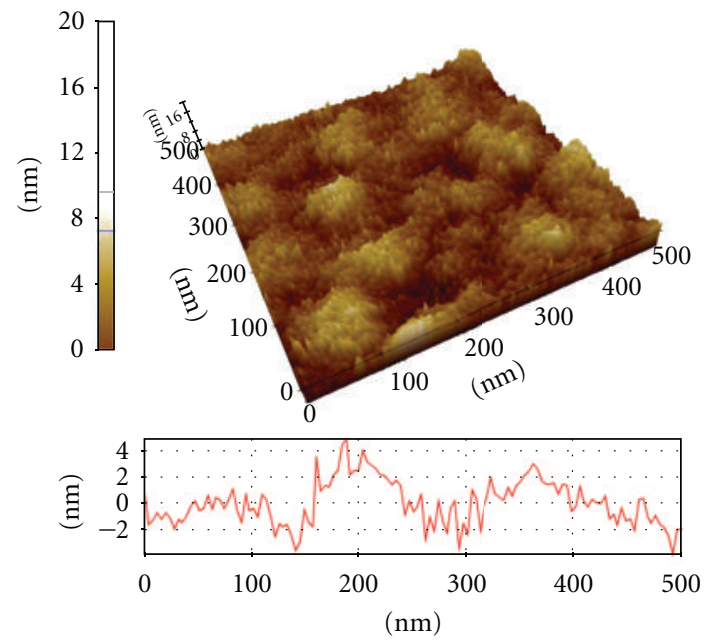

(c)

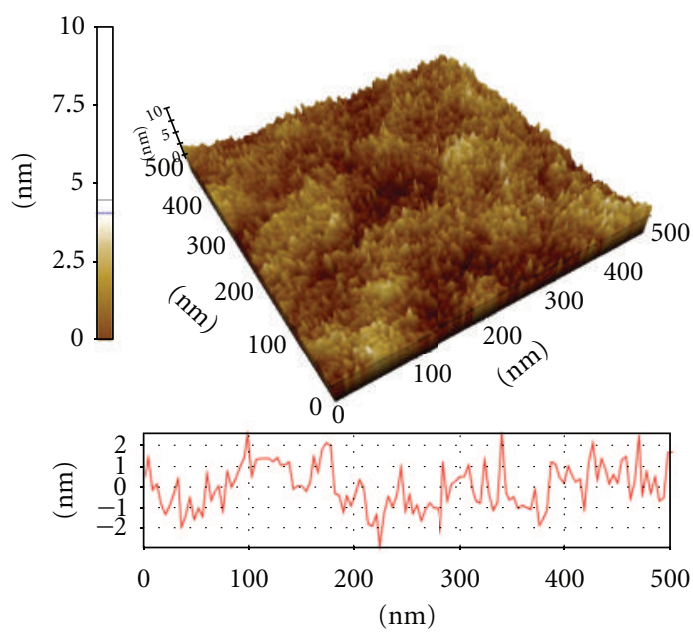

(b)

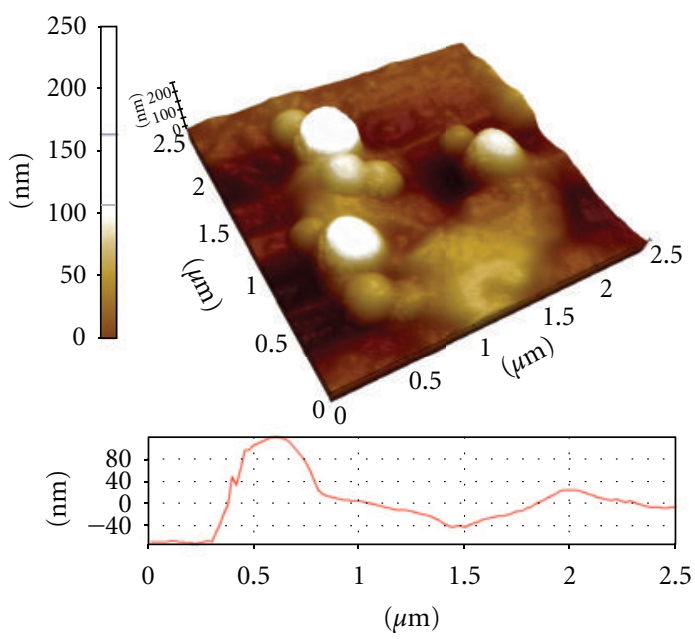

(d)

Figure 5: AFM image of (a) bare glass chip surface (scan size: $500 \mathrm{~nm} \times 500 \mathrm{~nm}$ ), (b) APTES/GA modified glass chip surface (scan size: $500 \mathrm{~nm} \times 500 \mathrm{~nm}),(\mathrm{c})$ immobilized protein A layer (scan size: $500 \mathrm{~nm} \times 500 \mathrm{~nm}$ ), and (d) CdSe/ZnS QDs with sandwich-type immunoassay (scan size: $2.5 \mu \mathrm{m} \times 2.5 \mu \mathrm{m}$ ).

were estimated to be $\sim 200.7 \pm 9.7 \mathrm{~nm}$ and $\sim 414.1 \pm 5.2 \mathrm{~nm}$, respectively. The height of nanoparticles with AFM analysis was relatively smaller than that with DLS (PS-COOH \#3, $D_{\mathrm{h}} \approx 250 \mathrm{~nm}$ ). The difference is because of the alteration of wetting degree for PS particles, since the $D_{\mathrm{h}}$ of swollen particles in the liquid phase caused about a $\sim 15 \%$ size increase [40]. It was also reported that a relative error between the actual dimension and AFM measurement value was due to a resolution limitation. The resolution limitation in AFM was $\sim 5 \%$ in height and $\sim 28 \%$ in width of the PS particles $[41,42]$. It could obviously be dependent on the AFM resolution as well.

The sensitivity of CdSe/ZnS/PS-COOH immunosensor was evaluated using a sandwich type solid phase immunoassay for various concentrations of detection anti-cTnI and cTnI antigens. The anti-cTnI antibody was immobilized on the surface of $\mathrm{CdSe} / \mathrm{ZnS} / \mathrm{PS}-\mathrm{COOH}$ immunosensor via covalent bonding between carboxyl group on immunosensor surface and amino group on antibody via EDC/NHS. Immune reaction between cTnI antigen and anti-cTnI antibody followed the schematic diagram in Figure 1(b) to detect the amount of cTnI antigens. Typical fluorescence signals for $\sim 4.5 \mu \mathrm{L}\left(\sim 1.08 \times 10^{12}\right.$ molecules $)$ and $\sim 2.25 \mu \mathrm{L}$ $\left(\sim 5.42 \times 10^{11}\right.$ molecules $)$ of detection anti-cTnI layer condition indicated a successful completion of the immunoassay as shown in Figure 6. The biological activity of detection anti-cTnI was properly maintained because of the presence of protein A layer. The existence of protein A on APTES/GA layer could induce biologically-active orientation of antibody by increasing binding affinity to the $\mathrm{Fc}$ fragment of detection anti-cTnI antibody [18]. The fluorescence intensity of the immunoassay with $\sim 4.5-\mu \mathrm{L}$ detection anti-cTnI was almost two times higher than that with $\sim 2.25-\mu \mathrm{L}$ anti-cTnI, as it was represented by the 3D surface plot. In Figure 6(a), the inset image of the scanned fluorescent intensities with $\sim 4.5$ $\mu \mathrm{L}$ detection anti-cTnI on the chip displayed the fluorescence 


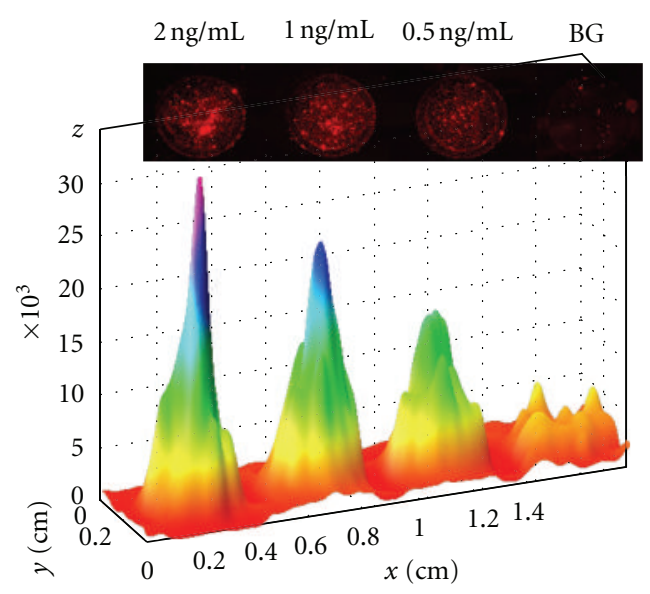

(a)

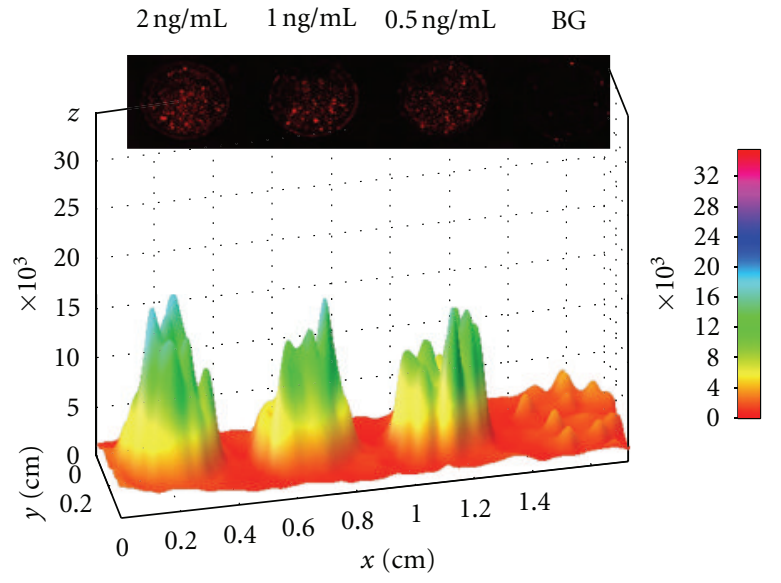

(b)

FIGURE 6: Reconstructed 3D surface plot images from the Image J represent fluorescence intensity. Volume of detection anti-cTnI (H86625M) on chip was (a) $\sim 4.5 \mu \mathrm{L}$ and (b) $\sim 2.25 \mu \mathrm{L}$. The $x$-axis represented the distance along the line, and the $y$-axis was the pixel intensity. Spots on the inset images were the scanned fluorescence intensity of immunoassay by ArrayWx.

enhancement as the concentration of target molecule was increased. The result was similar to the previous report [19]. On the other hand, no major changes of fluorescence intensity for $\sim 2.25-\mu \mathrm{L}$ detection anti-cTnI on the chip were observed (inset, Figure 6(b)). This result indicated that $\sim 2.25-\mu \mathrm{L}$ detection anti-cTnI, corresponding to $5.42 \times 10^{11}$ molecules, was not sufficient to fully cover the previously established protein A of $3.5 \times 10^{11}$ molecules. Therefore, the biosensing result suggested that the amount of detection anti-cTnI should be higher than $\sim 2.25 \mu \mathrm{L}$ to display distinctive immunoassay results. It was important to observe that there was very weak fluorescence signal with HSA. It clearly indicated the specific binding of QD/PS-COOH immunosensor with cTnI antigen without cross-reactivity with other types of antigen.

\section{Concluding Remarks}

On chip-based biosensor system with solid-phase immunoassay is of great interest for biomedical and clinical applications. A sandwich-type solid-phase immunoassay using $\mathrm{CdSe} / \mathrm{ZnS} / \mathrm{PS}-\mathrm{COOH}$ fluorophores was demonstrated for detecting cTnI using a fluorescence readout technique. The $\mathrm{CdSe} / \mathrm{ZnS} / \mathrm{PS}-\mathrm{COOH}$ immunosensor provided high sensitivity at the target cTnI concentration level of $\sim \mathrm{ng} / \mathrm{mL}$ as a diagnostic chip for monitoring cardiovascular disease.

\section{Acknowledgments}

The work at Hampton University was supported by the National Science Foundation (HRD-1137747) and the Army Research Office (W911NF-11-1-0177) in USA.

\section{References}

[1] C. Padeste, A. Grubelnik, and L. Tiefenauer, "Ferrocene-avidin conjugates for bioelectrochemical applications," Biosensors and Bioelectronics, vol. 15, no. 9-10, pp. 431-438, 2000.
[2] E. Mallat, D. Barceló, C. Barzen, G. Gauglitz, and R. Abuknesha, "Immunosensors for pesticide determination in natural waters,” TrAC, vol. 20, no. 3, pp. 124-132, 2001.

[3] F. Darain, P. Yager, K. L. Gan, and S. C. Tjin, "On-chip detection of myoglobin based on fluorescence," Biosensors and Bioelectronics, vol. 24, no. 6, pp. 1744-1750, 2009.

[4] E. Turiel, P. Fernández, C. Pérez-Conde, A. M. Gutiérrez, and C. Cámara, "Flow-through fluorescence immunosensor for atrazine determination," Talanta, vol. 47, no. 5, pp. 1255-1261, 1998.

[5] A. J. Ozinskas, "Principles of fluorescence immunoassay," in Topics in Fluorescence Spectroscopy, pp. 449-496, Springer, New York, NY, USA, 2002.

[6] I. L. Medintz, H. T. Uyeda, E. R. Goldman, and H. Mattoussi, "Quantum dot bioconjugates for imaging, labelling and sensing," Nature Materials, vol. 4, no. 6, pp. 435-446, 2005.

[7] X. Michalet, F. F. Pinaud, L. A. Bentolila et al., "Quantum dots for live cells, in vivo imaging, and diagnostics," Science, vol. 307, no. 5709, pp. 538-544, 2005.

[8] Z. Wu, Y. Zhao, F. Qiu et al., "Forming water-soluble CdSe/ZnS QDs using amphiphilic polymers, stearyl methacrylate/methylacrylate copolymers with different hydrophobic moiety ratios and their optical properties and stability," Colloids and Surfaces A, vol. 350, no. 1-3, pp. 121-129, 2009.

[9] E. R. Goldman, I. L. Medintz, and H. Mattoussi, "Luminescent quantum dots in immunoassays," Analytical and Bioanalytical Chemistry, vol. 384, no. 3, pp. 560-563, 2006.

[10] M. Ge, Y. Yue, Y. Liu et al., "Facile capping CdS and ZnS shells by thermolysis of ethylxanthate precursors for CdSe/CdS/ZnS nanocrystals," Colloids and Surfaces A, vol. 384, no. 1-3, pp. 574-579, 2011.

[11] H. Q. Wang, J. H. Wang, Y. Q. Li et al., "Multi-color encoding of polystyrene microbeads with $\mathrm{CdSe} / \mathrm{ZnS}$ quantum dots and its application in immunoassay," Journal of Colloid and Interface Science, vol. 316, no. 2, pp. 622-627, 2007.

[12] H. Fujiwara, H. Ohta, T. Chiba, and K. Sasaki, "Temporal response analysis of trap states of single CdSe/ZnS quantum dots on a thin metal substrate," Journal of Photochemistry and Photobiology A, vol. 221, no. 2-3, pp. 160-163, 2011. 
[13] M. Han, X. Gao, J. Z. Su, and S. Nie, "Quantum-dot-tagged microbeads for multiplexed optical coding of biomolecules," Nature Biotechnology, vol. 19, no. 7, pp. 631-635, 2001.

[14] Q. Nie, W. B. Tan, and Y. Zhang, "Synthesis and characterization of monodisperse chitosan nanoparticles with embedded quantum dots," Nanotechnology, vol. 17, no. 1, pp. 140-144, 2006.

[15] Z. Zhang, Y. Long, J. Pan, and X. Yan, "Preparation of fluorescence-encoded microspheres in a core-shell structure for suspension arrays," Journal of Materials Chemistry, vol. 20, no. 6, pp. 1179-1185, 2010.

[16] D. Polpanich, P. Tangboriboonrat, and A. Elaïssari, "The effect of acrylic acid amount on the colloidal properties of polystyrene latex," Colloid and Polymer Science, vol. 284, no. 2, pp. 183-191, 2005.

[17] J. S. Song, L. Chagal, and M. A. Winnik, "Monodisperse micrometer-size carboxyl-functionalized polystyrene particles obtained by two-stage dispersion polymerization," Macromolecules, vol. 39, no. 17, pp. 5729-5737, 2006.

[18] L. S. Jang and H. J. Liu, "Fabrication of protein chips based on 3-aminopropyltriethoxysilane as a monolayer," Biomedical Microdevices, vol. 11, no. 2, pp. 331-338, 2009.

[19] D. P. Tang, R. Yuan, and Y. Q. Chai, "Novel immunoassay for carcinoembryonic antigen based on protein A-conjugated immunosensor chip by surface plasmon resonance and cyclic voltammetry," Bioprocess and Biosystems Engineering, vol. 28, no. 5, pp. 315-321, 2006.

[20] C. Aybay, "Differential binding characteristics of protein G and protein A for $\mathrm{Fc}$ fragments of papain-digested mouse IgG," Immunology Letters, vol. 85, no. 3, pp. 231-235, 2003.

[21] J. S. Vesaratchanon, K. Takamura, and N. Willenbacher, "Surface characterization of functionalized latexes with different surface functionalities using rheometry and dynamic light scattering," Journal of Colloid and Interface Science, vol. 345, no. 2, pp. 214-221, 2010.

[22] M. S. Romero-Cano, A. Martin-Rodriguez, G. Chauveteau, and F. J. De Las Nieves, "Electrokinetic characterization of polystyrene-non-ionic surfactant complexes," Colloids and Surfaces A, vol. 140, no. 1-3, pp. 347-356, 1998.

[23] M. S. Romero-Cano, A. Martín-Rodríguez, G. Chauveteau, and F. J. De Las Nieves, "Colloidal stabilization of polystyrene particles by adsorption of nonionic surfactant: II. Electrosteric stability studies," Journal of Colloid and Interface Science, vol. 198, no. 2, pp. 273-281, 1998.

[24] P. H. Wang and C. Y. Pan, "Emulsion copolymerization of styrene with acrylic or methacrylic acids-distribution of the carboxylic group," Colloid and Polymer Science, vol. 279, no. 1, pp. 98-103, 2001.

[25] F. Samir, M. Morsli, J. C. Bernède, A. Bonnet, and S. Lefrant, "X-ray photoelectron spectroscopy of polybithiophene-polystyrene composites," Journal of Applied Polymer Science, vol. 66, no. 10, pp. 1839-1845, 1997.

[26] R. Daw, S. Candan, A. J. Beck et al., "Plasma copolymer surfaces of acrylic acid/1,7 octadiene: surface characterisation and the attachment of ROS 17/2.8 osteoblast-like cells," Biomaterials, vol. 19, no. 19, pp. 1717-1725, 1998.

[27] P. H. Wang and C. Y. Pan, "Preparation of styrene/acrylic acid copolymer microspheres: polymerization mechanism and carboxyl group distribution," Colloid and Polymer Science, vol. 280, no. 2, pp. 152-159, 2002.

[28] Y. Chen, T. Ji, and Z. Rosenzweig, "Synthesis of glyconanospheres containing luminescent CdSe-ZnS quantum dots," Nano Letters, vol. 3, no. 5, pp. 581-584, 2003.
[29] W. Sheng, S. Kim, J. Lee, S. W. Kim, K. Jensen, and M. G. Bawendi, "In-situ encapsulation of quantum dots into polymer microspheres," Langmuir, vol. 22, no. 8, pp. 3782-3790, 2006.

[30] N. Duxin, F. Liu, H. Vali, and A. Eisenberg, "Cadmium sulphide quantum dots in morphologically tunable triblock copolymer aggregates," Journal of the American Chemical Society, vol. 127, no. 28, pp. 10063-10069, 2005.

[31] F. Antolini, M. Pentimalli, T. Di Luccio et al., "Structural characterization of CdS nanoparticles grown in polystyrene matrix by thermolytic synthesis," Materials Letters, vol. 59, no. 24-25, pp. 3181-3187, 2005.

[32] S. H. Yu, M. Yoshimura, J. M. C. Moreno, T. Fujiwara, T. Fujino, and R. Teranishi, "In situ fabrication and optical properties of a novel polystyrene/semiconductor nanocomposite embedded with CdS nanowires by a soft solution processing route," Langmuir, vol. 17, no. 5, pp. 1700-1707, 2001.

[33] Z. Lei, X. Wei, Y. Fan, Y. Liu, and S. Bi, "Fabrication of CdSe composite by using the amphiphilic block copolymer as template," Journal of Colloid and Interface Science, vol. 304, no. 2, pp. 402-407, 2006.

[34] W. Luan, H. Yang, N. Fan, and S. T. Tu, "Synthesis of efficiently green luminescent $\mathrm{CdSe} / \mathrm{ZnS}$ nanocrystals via microfluidic reaction," Nanoscale Research Letters, vol. 3, no. 4, pp. 134-139, 2008.

[35] C. Q. Zhu, P. Wang, X. Wang, and Y. Li, "Facile phosphinefree synthesis of CdSe/ZnS core/shell nanocrystals without precursor injection," Nanoscale Research Letters, vol. 3, no. 6, pp. 213-220, 2008.

[36] L. Blasi, L. Longo, P. P. Pompa et al., "Formation and characterization of glutamate dehydrogenase monolayers on silicon supports," Biosensors and Bioelectronics, vol. 21, no. 1, pp. 30-40, 2005.

[37] S. Ohnishi, M. Murata, and M. Hato, "Correlation between surface morphology and surface forces of protein a adsorbed on mica," Biophysical Journal, vol. 74, no. 1, pp. 455-465, 1998.

[38] M. C. Coen, R. Lehmann, P. Gröning, M. Bielmann, C. Galli, and L. Schlapbach, "Adsorption and bioactivity of protein A on silicon surfaces studied by AFM and XPS," Journal of Colloid and Interface Science, vol. 233, no. 2, pp. 180-189, 2001.

[39] W. Lee, B. K. Oh, Y. M. Bae, S. H. Paek, W. H. Lee, and J. W. Choi, "Fabrication of self-assembled protein A monolayer and its application as an immunosensor," Biosensors and Bioelectronics, vol. 19, no. 3, pp. 185-192, 2003.

[40] J. R. Li, G. C. Henry, and J. C. Garno, "Fabrication of nanopatterned films of bovine serum albumin and staphylococcal protein a using latex particle lithography," Analyst, vol. 131, no. 2, pp. 244-250, 2006.

[41] K. A. Ramirez-Aguilar and K. L. Rowlen, "Tip characterization from AFM images of nanometric spherical particles," Langmuir, vol. 14, no. 9, pp. 2562-2566, 1998.

[42] K. Saal, V. Sammelselg, A. Lõhmus et al., "Characterization of glucose oxidase immobilization onto mica carrier by atomic force microscopy and kinetic studies," Biomolecular Engineering, vol. 19, no. 2-6, pp. 195-199, 2002. 

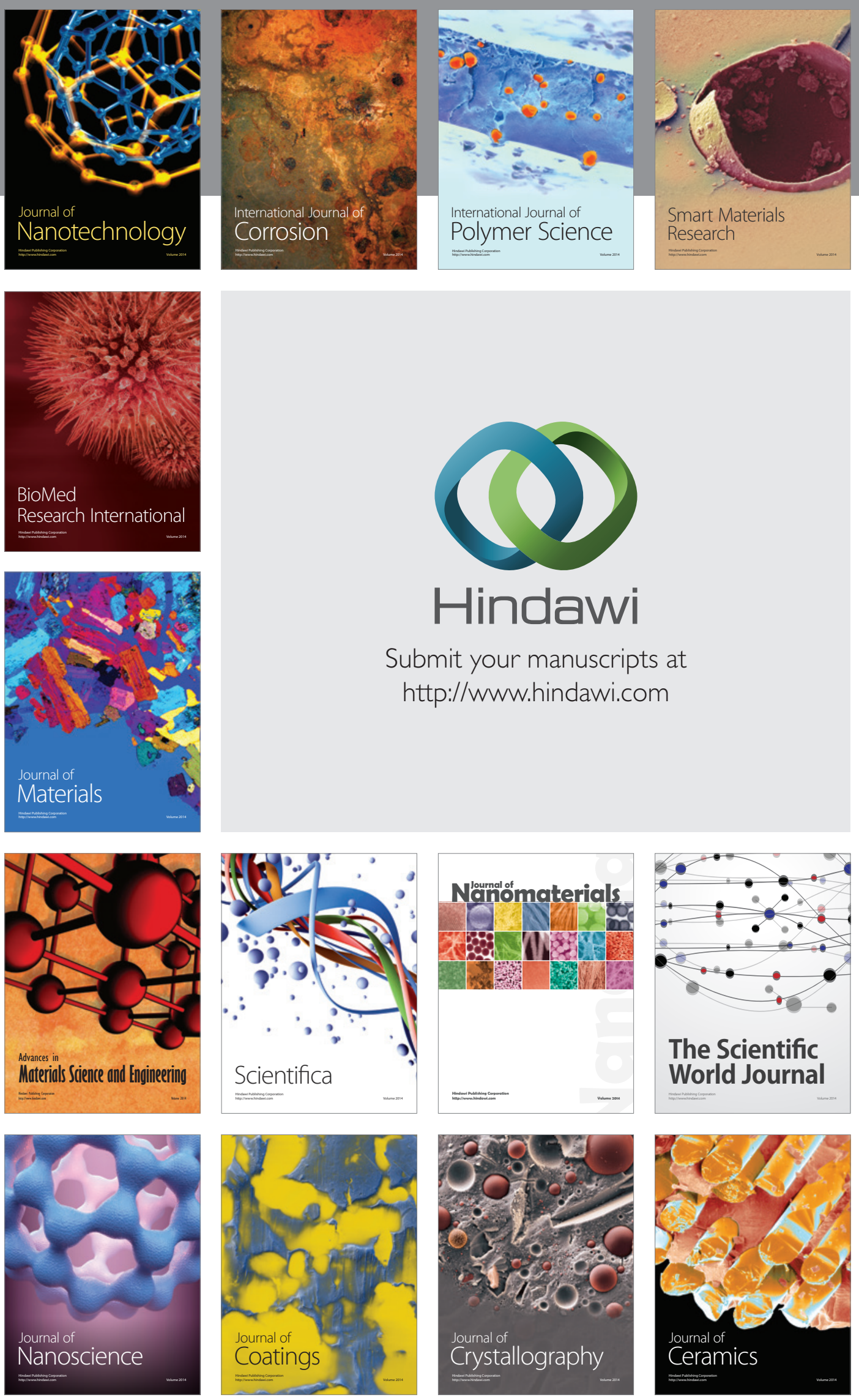

The Scientific World Journal

Submit your manuscripts at

http://www.hindawi.com

\section{World Journal}

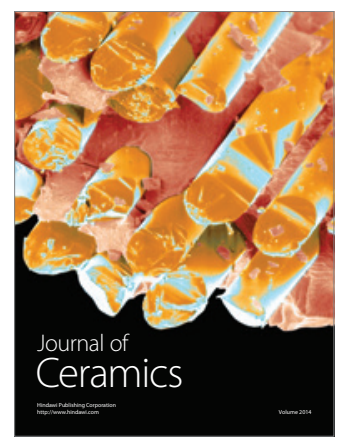

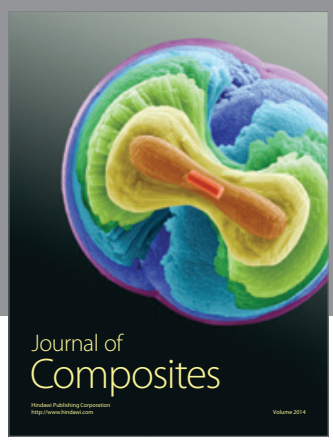
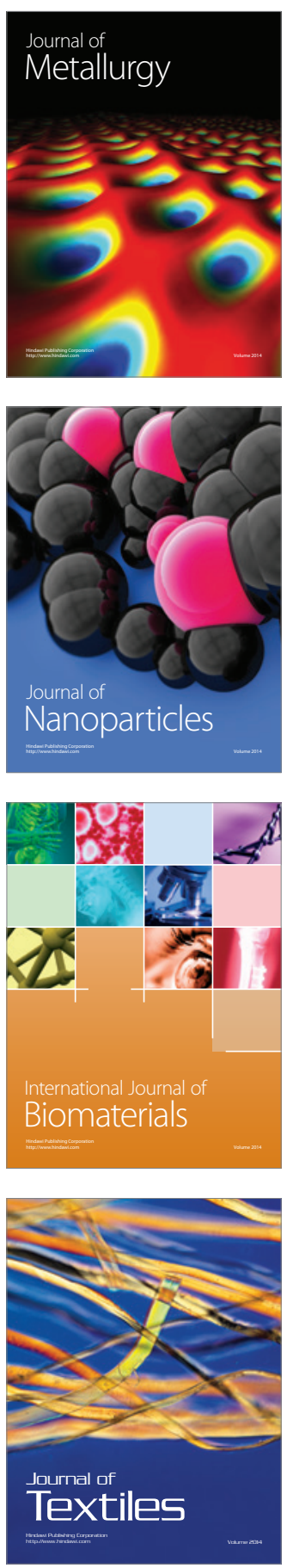